\title{
A CONVENIENT METHOD OF MEASURING QUANTUM YIELDS OF PHOTOISOMERIZATION OF trans-STILBENE
}

TONG-ING HO, TZU-MIN SU and TIAN-CHYUAN HWANG

Department of Chemistry, National Taiwan University, Taipei, Taiwan, 10764 (China)

(Received February 11, 1987; in revised form September 10, 1987)

\section{Summary}

A novel and convenient method of measuring quantum yields of photoisomerization of trans-stilbene was developed by using a monochromic nitrogen laser light source and a pulsed energy meter. The method has high accuracy without the need to employ chemical actinometers.

\section{Introduction}

Photoinduced trans-cis isomerization is one of the most fundamental processes in photochemical and photophysical systems. One of the most thoroughly studied photoisomerizations is the trans-cis isomerization of trans-stilbene (TS) [1 - 15]:

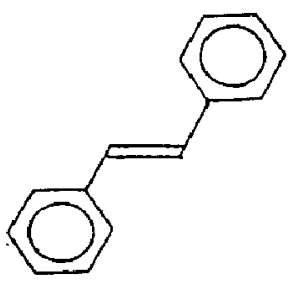

TS
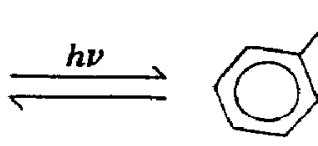

CS

The photoisomerization of TS can be effected either by direct photolysis $[1-4,7,9]$ or by sensitization $[5,6,8,9,11-14]$. For TS the singlet pathway for trans-cis photoisomerization in liquid solutions was established by Saltiel and coworkers [1].

$\mathrm{TS} \stackrel{h \nu}{\longrightarrow}{ }^{1}(\mathrm{TS})^{*} \longrightarrow{ }^{1} \mathrm{P}^{*} \longrightarrow{ }^{1} \mathrm{P} \longrightarrow(1-\beta) \mathrm{CS}$

where ${ }^{1} \mathrm{P}^{*}$ is the twisted excited singlet state, ${ }^{1} \mathbf{P}$ is the twisted ground state and $1-\beta$ the fraction of ${ }^{1} \mathbf{P}^{*}$ decaying to $\mathrm{CS}$. For the substituted stilbenes, Saltiel and Charlton [16] have divided the reactions into three groups according to the effect of the substituent on the singlet-to-triplet intersystem crossing; substituents cause deviations from planarity because of steric effects. For the para-halogenated stilbenes the quantum yield of intersystem 
crossing to an upper excited triplet state is substantial because of the heavy atom effect. For $p$-nitrostilbenes the trans-cis photoisomerization occurs via the lowest triplet pathway while for $p$-cyanostilbenes it is similar to that of unsubstituted TS [9].

Since TS could be used as a chemical actinometer [17 - 19], accurate measurements of its photoisomerization quantum yields are necessary. Although measurements of the isomerization quantum yields of TS have already been reported [16, $20-24]$, we would like to report a convenient and accurate method of measuring the trans-cis isomerization quantum yields of TS.

\section{Experimental details}

All the para-substituted trans-stilbenes were prepared from corresponding para-substituted benzaldehydes and benzyl chloride by the Wittig reaction [25]. Solvents used were of LC grade or Spectrograde (Merck) and were used as received. We used a home-made pulsed UV $(337.1 \mathrm{~nm})$ molecular nitrogen laser or a VSL-337 instrument (Laser Science, Inc.). The construction procedure for the home-made laser has been published elsewhere [26]; it has a pulse duration of $6 \mathrm{~ns}$ and a peak power of $500 \mathrm{~kW} \mathrm{(3 \textrm {mJ } \text { per }}$ shot). The VSL-337 laser has a pulse length of $3 \mathrm{~ns}$ and a peak output power of $40 \mathrm{~kW}$ (pulse energy, $120 \mu \mathrm{J}$ ). The rectangular laser beam has dimensions of $3 \mathrm{~mm} \times 8 \mathrm{~mm}$. The illuminated area can be adjusted so that it does not exceed $1 \mathrm{~cm} \times 1 \mathrm{~cm}$. TS samples $\left(10^{-2} \mathrm{M}\right)$ were outgassed by $\mathrm{N}_{2}$. The laser light intensity absorbed by the sample can be measured by a pulsed energy meter (Laser Precision Corporation) with an RJ-7100 energy readout and an RJP-734 energy probe. The spectral response of the cavity detector has an error of $\pm 0.5 \%$ in the range $0.4-3 \mu \mathrm{m}$. The pulsed energy meter was factory calibrated just before use. The absolute energy of the home-made laser pulse was calibrated by a ferrioxalate actinometer [26] and its typical energy is $2.5 \mathrm{~mJ}$ per shot (operating at $10.5 \mathrm{kV}, 25$ Torr $\mathrm{N}_{2}$ ). The typical dose absorbed by the sample was $5.6 \times 10^{15}$ photons per pulse with the home-made laser.

Irradiated solutions were analysed by gas chromatography (GC) with a Hitachi 163 dual-flame instrument fitted with a flame ionization detector and SE-30 on a Chromosorb W column $(1 \mathrm{~m})$. Under these analytical conditions TS has a longer retention time than CS and it is separated well. The integration area of the reaction product was determined by the cut and weigh method. In the GC analyses it was assumed that the TS and their photoisomers CS are equally sensitive to flame ionization detection. This has been shown to be true for the unsubstituted TS. The extent of reaction is determined by the disappearance of TS and/or the formation of CS. To determine the extent of product formation, an internal standard (e.g. hexadecane, eicosane etc.) was utilized and the response factor $k$ was calculated from the following proportionality relationships: 
Before photolysis

$\frac{\text { Area TS }}{\text { Area internal standard }}=k \frac{\text { Moles TS }}{\text { Moles internal standard }}$

After photolysis

Moles product $=\frac{1}{k} \frac{\text { Area product }}{\text { Area internal standard }} \times$ Moles internal standard

The $k$ factors thus calculated for the stilbenes are 0.7254 (TS), 0.6784 ( $p$-methoxy TS), 0.8010 ( $p$-chloro TS), 0.9623 ( $m$-chloro TS) and 1.0317 ( $p$-isopropyl TS). The ratio of millimoles of product formed to millieinsteins of light absorbed gives the quantum yield.

\section{Results and discussion}

There are two major concerns about conventional quantum yield measurements. The first is the monochromicity of the light source and the second is the accuracy of the chemical actinometer used. Usually, monochromic light is isolated by a filter solution, for example the $313 \mathrm{~nm}$ band isolated from $\mathrm{K}_{3} \mathrm{~F}_{\mathrm{e}}\left(\mathrm{C}_{2} \mathrm{O}_{4}\right)_{3}$ in $1 \mathrm{~N} \mathrm{H}_{2} \mathrm{SO}$ [27] or from potassium chromate solution [28]. The monochromator (Schoeffel; bandwidth, $7 \mathrm{~nm}$ ) combined with a high pressure $\mathrm{Xe}-\mathrm{Hg}$ lamp to isolate the monochromic light can also be used [15]. A combination of various kinds of commercially available filters [29] has been used. Often if the light source has a large bandwidth large errors in the quantum yields may be caused and corrections must be made. The accuracy of measurement of the quantum yields also depends on the accuracy of the actinometer [30]. Important chemical actinometers are ferrioxalate [27], benzophenone-benzhydrol [31], valerophenone [32], stilbene [18] and Aberchrome 540 reusable system [30]. For the much-used ferrioxalate system, an error of larger than $40 \%$ has been reported [33] with improper handling.

Absolute quantum yields were determined for outgassed samples contained in a quartz cell using the nitrogen $337.1 \mathrm{~nm}$ laser pulse. The pulsed nitrogen laser [26] provides monochromic light with a very small bandwidth $( \pm 0.1 \mathrm{~nm})$ and is suitable for quantum yield measurements. The light intensity was monitored by the pulsed energy meter before and after the sample was charged, so the energy absorbed by the sample can be obtained and the reflected light in the sample cell can thus be cancelled [30]. The reaction was carried out to less than $5 \%$ conversion of original TS. The product concentration was determined by GC. The quantum yields of trans-to-cis isomerization of TS in different solvents were obtained and compared with the published results (Table 1). 
TABLE 1

$\phi_{t \rightarrow c}$ for trans-stilbene in various solvents at various wavelengths ${ }^{a}$

\begin{tabular}{llll}
\hline Solvent & $\begin{array}{l}\text { Wavelength } \\
(\mathrm{nm})\end{array}$ & $\phi_{\mathrm{t} \rightarrow \mathrm{c}}$ Reference \\
\hline Ethyl acetate & 337.1 & 0.62 & This work \\
Methanol & 337.1 & 0.56 & This work \\
Acetonitrile & 337.1 & 0.56 & This work \\
Ethanol & 337.1 & 0.52 & This work \\
Ether & 337.1 & 0.52 & This work \\
n-Hexane & 337.1 & 0.50 & This work \\
n-Hexane & 313 & 0.47 Dyck and McClure [22] \\
n-Hexane & 313 & 0.27 Yamashita [23] \\
n-Hexane & 313 & 0.59 & Stegemeyer [24] \\
n-Hexane & 254 & 0.67 & Stegemeyer [24] \\
Cyclohexane & 313 & 0.40 Guisten and Klasinc [20] \\
50vol.\%methanol-50vol.\%ethanol & 313 & 0.50 Gegiou, Muszkat and Fischer [21] \\
\hline
\end{tabular}

${ }^{a}$ A home-made $\mathrm{N}_{2}$ laser provided the $337.1 \mathrm{~nm}$ light $(500 \mathrm{~kW})$.

Substituted TS were preapred [25]; the molar extinction coefficients for the substituted stilbenes at $337 \mathrm{~nm}$ are 956 ( $p$-methoxy), 341 ( $p$-chloro), $116\left(\mathrm{~m}\right.$-chloro) and $138\left(p\right.$-isopropyl) $1 \mathrm{~mol}^{-1} \mathrm{~cm}^{-1}$. The concentrations used for quantum yield studies were less than $10^{-2} \mathrm{M}$, so the optical density at $337 \mathrm{~nm}$ is less than 4 (except for $p$-methoxy TS) and the quantum yield for dimerization is less than 0.01 [18]. The quantum yields were obtained by the same method and compared with published data (Table 2).

Since the saturation effect [34] of the pulsed laser might have interfered, we employed a less powerful laser (VSL-337) to check the dependence of the conversion on the incident laser energy (Table 3 ). The results indicate that the quantum yields are the same and are independent of the incident laser energy. The quantum yields remained the same when TS concentrations of less than $10^{-2} \mathrm{M}$ were employed.

There are several major sources of error in the quantum yield measurements: (1) the accuracy of the laser energy measurements is $4 \%$; (2) the accuracy of the product formation measurements is $6 \%$ (including balance (2\%), pipette $(0.9 \%)$ and volumetric flask $(0.2 \%))$. The total percentage error is estimated to be $10 \%$ and is better than the conventional value of $20 \%$ [29].

This fast and convenient method of measuring quantum yields is suitable for other systems. Other lasers can also be employed. For example we have measured the absolute quantum yields of the amine addition reaction of cyclohexenone by using an Nd-YAG laser [35].

\section{Acknowledgments}

The authors are grateful for financial support from the National Science Council of the Republic of China, and T.-I. H. expresses his gratitude to 
TABLE 2

Quantum yields for trans-cis isomerization of mono-substituted trans-stilbenes ${ }^{a}$

\begin{tabular}{|c|c|c|c|c|}
\hline $\boldsymbol{R}$ & $\begin{array}{l}\text { Wavelength } \\
(\mathrm{nm})\end{array}$ & Solvent & $\phi_{\mathbf{t} \rightarrow \mathbf{c}}$ & Reference \\
\hline$p-\mathrm{CH}_{3} \mathrm{O}$ & 313 & Cyclohexane & 0.40 & Güsten and Klasinc [20] \\
\hline p.Cl & 313 & Cyclohexane & 0.41 & Güsten and Klasinc [20] \\
\hline$m-\mathrm{Cl}$ & 313 & Cyclohexane & 0.40 & Güsten and Klasinc [20] \\
\hline$p-\mathrm{CH}_{3} \mathrm{O}$ & 313 & $\begin{array}{l}\text { 50vol.\%methanol- } \\
\text { 50vol.\%ethanol }\end{array}$ & 0.46 & Gegiou, Muszkat and Fischer [ 21 ] \\
\hline$p-\mathrm{Cl}$ & 313 & $\begin{array}{c}\text { 50vol.\%methanol- } \\
50 \mathrm{vol} \text { \%ethanol }\end{array}$ & 0.60 & Gegiou, Muszkat and Fischer [21] \\
\hline$p-\mathbf{B r}$ & 313 & $\begin{array}{c}\text { 50vol.\%methanol- } \\
\text { 50vol.\%ethanol }\end{array}$ & 0.35 & Gegiou, Muszkat and Fischer [21] \\
\hline$p \cdot \mathrm{CH}_{3}$ & 337.1 & Ethyl acetate & 0.64 & This work \\
\hline$p-\mathrm{CH}_{3}$ & 337.1 & Acetonitrile & 0.60 & This work \\
\hline$p-\mathrm{CH}_{3}$ & 337.1 & Ethanol & 0.59 & This work \\
\hline$p-\mathrm{CH}_{3}$ & 337.1 & n-Hexane & 0.55 & This work \\
\hline$p-\mathrm{CH}_{3}$ & 337.1 & Methanol & 0.61 & This work \\
\hline$p-\mathrm{CI}$ & 337.1 & Methanol & 0.60 & This work \\
\hline$p-\mathrm{CH}_{3} \mathrm{O}$ & 337.1 & Ethyl acetate & 0.58 & This work \\
\hline p-Isopropyl & 337.1 & Ethanol & 0.55 & This work \\
\hline$m-\mathrm{Cl}$ & 337.1 & Ethanol & 0.56 & This work \\
\hline
\end{tabular}

a home-made $\mathrm{N}_{2}$ laser provided the $337.1 \mathrm{~nm}$ light $(500 \mathrm{~kW})$.

TABLE 3

Quantum yields for trans-cis isomerization of monosubstituted trans-stilbenes at 337.1 nm using a $40 \mathrm{~kW}$ VSL-337 laser

\begin{tabular}{lllr}
\hline$R$ & Solvent & Concentration $(\mathrm{M})$ & $\phi_{\mathrm{t} \rightarrow \mathrm{c}}$ \\
\hline$p-\mathrm{CH}_{3} \mathrm{O}$ & Ethyl acetate & $10^{-2}$ & 0.61 \\
$p-\mathrm{CH}_{3} \mathrm{O}$ & Cyclohexane & $10^{-2}$ & 0.55 \\
$p-\mathrm{Cl}$ & Ethyl acetate & $10^{-2}$ & 0.60 \\
$p-\mathrm{Cl}$ & Cyclohexane & $10^{-2}$ & 0.47 \\
$m-\mathrm{Cl}$ & Ethyl acetate & $10^{-2}$ & 0.52 \\
$m-\mathrm{Cl}$ & Cyclohexane & $10^{-2}$ & 0.46 \\
$p$-Isopropyl & Ethyl acetate & $10^{-2}$ & 0.52 \\
$p$-Isopropyl & Cyclohexane & $10^{-2}$ & 0.54 \\
$p$-Isopropyl & Cyclohexane & $8 \times 10^{-3}$ & 0.55 \\
H & Cyclohexane & $10^{-2}$ & 0.64 \\
\hline
\end{tabular}

Chang-Min Liu and Hwei-Chuang Lee for technical assistance. The VSL-337 laser was borrowed from Professor $H$. Chang of National Tsing-Hwa University.

\section{References}

1 J. Saltiel and J. T. D'Agostino, J. Am. Chem. Soc., 94 (1972) 6445.

J. Saltiel, J. T. D'Agostino, E. D. Megarity, L. Metts, K. R. Neuberger, M. Wrighton and O. C. Zafiriou, Org. Photochem., 3 (1973) 1. 
J. Saltiel, D. W.-L. Chang, E. D. Megarity, A. D. Rousseau, P. T. Shannon, B. Thomas and A. K. Uriarte, Pure Appl. Chem., 41 (1975) 559.

A. Marinari and J. Saltiel, Mol. Photochem., 7 (1976) 225.

J. Saltiel, A. Marinari, D. W.-L. Chang, J. C. Mitchener and E. D. Megarity, J. Am. Chem. Soc., 101 (1979) 2982.

2 J. Saltiel, D. E. Townsend and A. Sykes, J. Am. Chem. Soc., 105 (1983) 2530.

3 J. Troe, Chem. Phys. Lett., 114 (1985) 241.

4 G. Rothenberger, D. K. Negus and R. M. Hochstrasser, J. Chem. Phys., 79 (11) (1983) 5360 .

5 S. Yamauchi and T. Azumi, d. Am. Chem. Soc., 95 (1973) 2709.

6 J. Saltiel, A. D. Rousseau and B. Thomas, J. Am. Chem. Soc., 105 (1983) 7631.

7 A. Amirav and J. Jortner, Chem. Phys. Lett., 95 (1983) 295.

8 H. Görner and D. Schulte-Frohlinde, J. Phys. Chem., 85 (1981) 1835.

9 H. Görner, J. Photochem., I3 (1980) 269.

10 G. Orlandi, P. Palmieri and G. Poggi, J. Am. Chem. Soc., 101 (1979) 3492.

11 W. G. Herkstroeter and G. S. Hammond, J. Am. Chem. Soc., 88 (1966) 4769.

12 G. S. Hammond and J. Saltiel, J. Am. Chem. Soc., 85 (1963) 2516.

D. Valentine and G. S. Hammond, J. Am. Chem. Soc., 94 (1972) 3449.

13 J. Saltiel, J. L. Charlton and W. B. Mueller, J. Am. Chem. Soc., 101 (1979) 1347.

14 V. Balzani and F. Bolletta, J. Am. Chem. Soc., 100 (1978) 7404.

15 H. Görner and D. Schulte-Frohlinde, Chem. Phys. Lett., 101 (1983) 79.

16 J. Saltiel and J. L. Charlton, in P. de Mayo (ed.), Rearrangements in Ground and Excited States, Vol. 3, Academic Press, New York, 1980, p. 25.

17 W. Hub, S. Schneider, F. Dörr, J. D. Oxman and F. D. Lewis, J. Am. Chem. Soc., 106 (1984) 701 .

18 F. D. Lewis and D. E. Johnson, J. Photochem., 7 (1977) 421.

19 W. Hub, S. Schneider, F. Dörr, J. D. Oxmann and F. D. Lewis, J. Am. Chem. Soc., 106 (1984) 708.

$20 \mathrm{H}$. Güsten and L. Klasinc, Tetrahedron Lett., (1968) 3097.

21 D. Gegiou, K. A. Muszkat and E. Fischer, J. Am. Chem. Soc., 90 (1968) 3907.

22 R. H. Dyck and D. S. McClure, J. Chem. Phys., 36 (1962) 2326.

23 S. Yamashita, Bull. Chem. Soc. Jpn., 34 (1961) 490.

24 H. Stegemeyer, J. Phys. Chem., 66 (1962) 2555.

25 T. I. Ho, C. M. Chang, S. R. Wang, C. P. Cheng, J. Chem. Soc., Dalton Trans, in the press.

26 C. J. Lai, Y. C. Wu, C. L. Yang and T. M. Su, Proc. Natl. Sci. Counc. ROC (A), 7 (1983) 163.

27 C. A. Parker and C. G. Hatchard, Proc. R. Soc. London, Ser. A, 245 (1956) 518.

28 F. D. Lewis and T. I. Ho, J. Am. Chem. Soc., 99 (1977) 7991.

29 B. S. Green, M. Rejto, D. E. Johnson, C. E. Hoyle, J. T. Simpson, P. E. Correa, T. I. Ho, F. MeCoy and F. D. Lewis, J. Am. Chem. Soc., 101 (1979) 3325.

30 W. M. Horspool, Synthetic Organic Photochemistry, Plenum, New York, 1984, p. 489.

31 W. M. Moore, G. S. Hammond and R. P. Foss, J. Am. Chem. Soc., 83 (1961) 2789.

32 P. J. Wagner and A. E. Kemppainer, J. Am. Chem. Soc., 90 (1968) 5896.

33 W. D. Bowman and J. N. Demas, J. Phys. Chem., 80 (1976) 2434.

34 R. Bensasson, C. R. Goldschmidt, E. J. Land and T. G. Truscott, Photochem. Photobiol., 28 (1978) 277.

35 T. I. Ho, Y. L, Chow and H. C. Lee, Proc. Natl. Sci. Counc. ROC (A), 10 (1986) 212. 